\title{
Rational use of medicines - Indian perspective!
}

\author{
G.P. Mohanta* and P.K. Manna \\ Department of Pharmacy, Annamalai University, Annamalai Nagar, India \\ *Corresponding author. E-mail: gpmohanta@hotmail.com
}

BACKGROUND: India, the largest democracy in the world, is with a federal structure of 29 states and 7 union territories. With a population of more than 1.2 billion, resource is always a constraint and so is in the health system too. In the federal structure, providing healthcare is largely the responsibility of state governments. Medicines are important component of health care delivery system and quality care is dependent on the availability and proper use of quality medicines. In spite of being known as pharmacy of the third world, poor access to medicines in the country is always a serious concern. Realizing the need of quality use of medicines, several initiatives have been initiated.

RESULTS: As early as 1994, seeds of rational use of medicines were sown in the country with two initiatives: establishment of a civil society, Delhi Society for Promoting Rational Use of Drugs (DSPURD) and establishment of government agency in Tamil Nadu, a southern state, called Tamil Medical Services Corporation Limited (TNMSCL). DSPUD was in official association with World Health Organization Country Office for implementing essential medicine programme in the country for two biennia. In addition to organizing sensitising and training programme for healthcare professionals throughout the country, it looked after the procurement and appropriate use of medicines in Delhi government health facilities. TNMSCL has made innovations in medicine management including procurement directly from manufacturers as a part of pooled procurement, establishing warehouses with modern storage facilities and Information Technology enabled management of whole process. TNMSCL Model is now replicated in almost the entire country and even in some small other countries as it is successful in improving access to medicines.

The National Government and the State Governments have developed strategies to promote rational use of medicines as a part of improving access and quality care in public health facilities. National Government developed policies and regulations for combating antimicrobial resistance, controlling the prices of medicines, establishing generic medicines stores and advocating for the need for improvement of medicine logistics at state level and prescription auditing system. There is wide variation in medicine procurement and management system among the states. Spending on medicines ranges from as small as $2 \%$ of health budget to as high as $17 \%$. The procurement system varies from individual facilities to partial pooled procurement to complete centralised system.

There are attempts of developing essential medicine lists, standard treatment guidelines and costing of treatment of common illnesses. Except for the few states, essential medicine list remains an ornamental showpiece. However, with apex court's intervention, the prices are now controlled for all 348 medicines listed in national list. The pharmaceutical companies continue to violate price regulations either through making the medicines at different strengths or new fixed dose combinations (FDCs). Perhaps the largest number of FDCs and many of them with no valid justification are available in the country. Decisions 
on compulsory licensing have made the new anticancer medicines affordable. Other countries have also benefited from this decision.

CONCLUSIONS: While some progress has been made for appropriate use of medicines in public health facilities, there are little efforts in private sectors and at community levels. Availability of prescription medicines without much control and free drug advertising are other concerns. Like all other countries irrational use of medicines continues to be of concern in India despite of several attempts of improving use of medicines both in the health system as well as in community. But efforts continue to be made for improving the use of medicines!

Keywords: Rational use of medicines, health system, improving use of medicines, medicine list

Conflict of interest statement: None. 